\title{
Proposal And Validity Of The Product Planning Business Model "A-POST" - The Application Of The Text Mining Method To Scooter Exterior Design-
}

\author{
Mari Nakamura, Aoyama Gakuin University, Japan \\ Masato Kuniyoshi, Aoyama Gakuin University, Japan \\ Manabu Yamaji, Aoyama Gakuin University, Japan \\ Kakuro Amasaka, Aoyama Gakuin University, Japan
}

\begin{abstract}
In this paper, the authors propose the product planning business model "A-POST", which captures the customers' tastes exactly and reflects them in the styling design of a product. Specifically, the authors have created a new product design concept using the text mining method which analyzes customer's opinions in a language state. As an example of the application of this research, the authors applied this method to the product design process of a new scooter and obtained the results shown.
\end{abstract}

Keywords: Product Planning Business Model “A-POST”, Text Mining, Scooter

\section{INTRODUCTION}

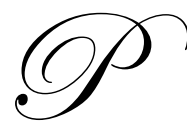

roduct development in automotive manufacturing is undergoing a transitional phase from functional quality and product-oriented development, which views the product as a means of transportation, to a kind of development that inspires or makes an impression on the customer. In order to respond to such a trend, it is essential to conduct a "scientific approach to customers' tastes" whereby the customers' tastes are accurately grasped and reflected in the product. This task is to be undertaken by the product planning and designing department. It is deemed important for the product planning department to determine the customers' desires in a precise manner, and to provide the designers with an exact product concept.

A study is being conducted on "Customer Science" (implicit knowledge - lingual knowledge - explicit knowledge) which takes a scientific approach to the customers' tastes, (implicit knowledge) by means of statistical science. [1-4] As a study case for this, the authors created the "Conceptual Support Method for Developing Strategic Product" and reflected it in the automotive styling (profile design). [5,6] Then a specific commercialization study was conducted through academic-industrial cooperation, and substantial results have been obtained in the "innovation of the design business process" for 4-wheel vehicles. [7, 8]

Based on the study results, the authors will deploy the "scientific approach to customers' tastes" by means of "Customer Science" aiming to achieve "innovation in the product planning business process". [9,10] More specifically, through joint research with a certain motorcycle manufacturer, "A", as it is called hereafter, the authors will attempt to create a "product planning business model". The motorcycle which the authors were consigned to develop was to have a "high-class and original style targeting the young generation: Model Name, X (on the market in 2006)". This is in connection with a new product development project for a 50cc-class scooter, which occupies over $70 \%$ of the market share of motorcycle sales volume by engine displacement. 


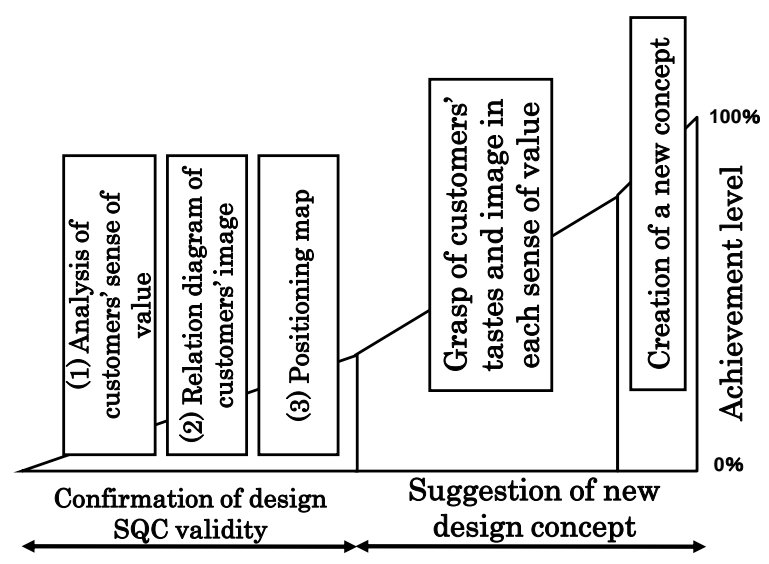

Fig. 1: Approaching "creation of a new design concept"

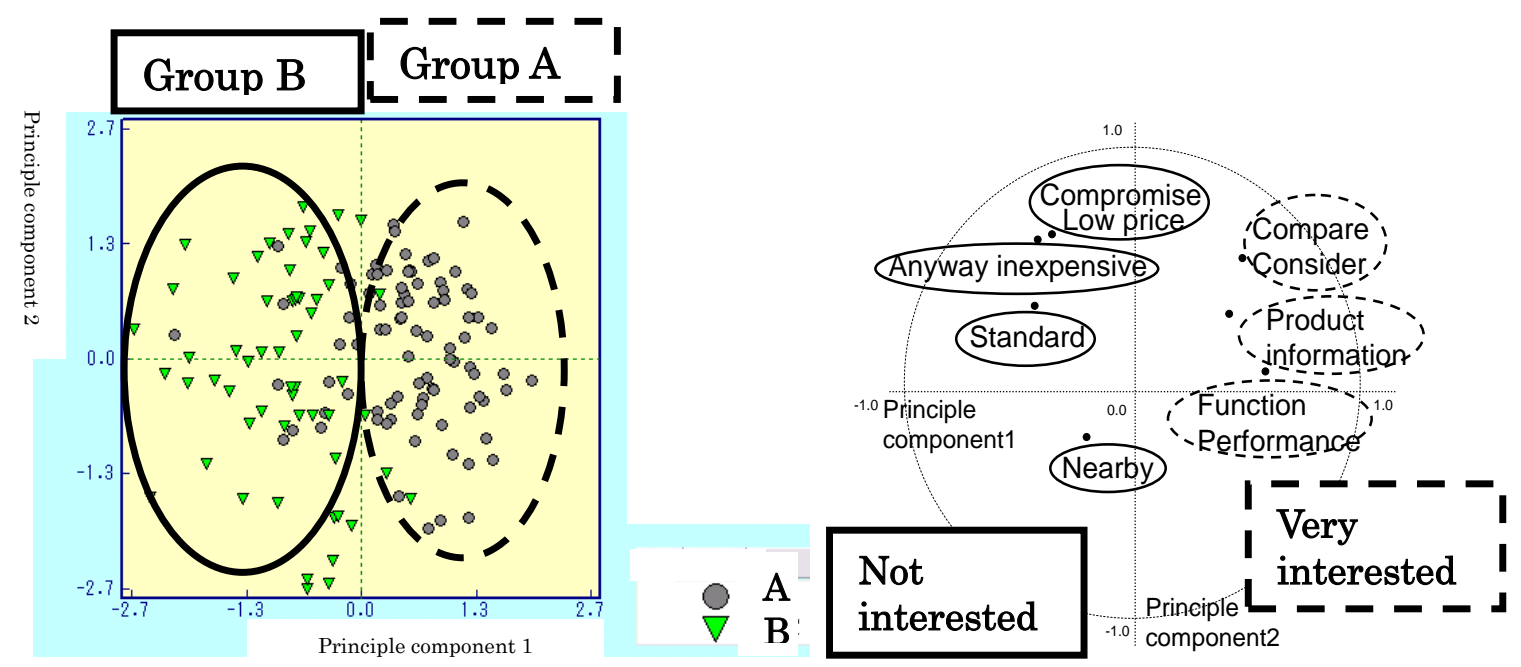

(a) Dispersed chart of the main component points

(b) Dispersed chart of the amount of factor load

Fig. 2: The meaning of each group according to principle component analysis

In order to conduct a concrete research project, the authors collaborated with Manufacturer A and a market research firm "B" to convert implicit knowledge of the customers' tastes into lingual knowledge through incorporation of statistical science. This was done in an attempt to convert into "explicit knowledge" or quantitatively grasp the external design style of the scooter so that the main element of product planning, "conceptualization of the profile design" could be carried out. In the implementation stage, an attempt was made to convert the "implicit knowledge" of customers' opinions into "linguistic knowledge" through the combined use of "text mining" and multivariate statistical analysis so as to create a "new design concept" for the new type scooter. Through these means, the product planning business process can be generalized, and then a "product planning business model - A-POST" (Amalab's Product Development Model Of the Scooter by the Text Mining Method) has been created. 


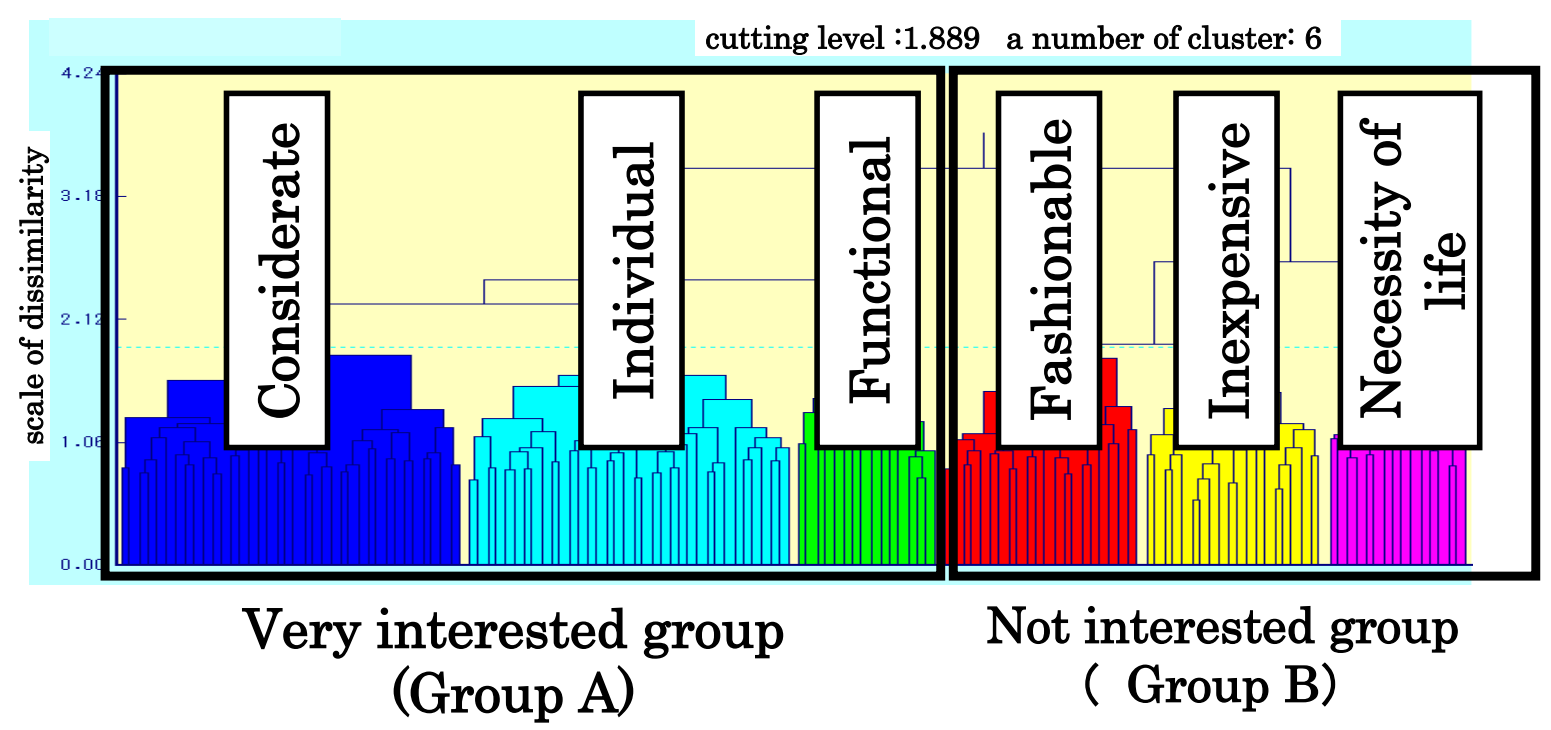

Fig. 3: Analysis of customers' sense of value

\section{STUDY GUIDELINES}

\subsection{Mountain Climbing Chart For Proposal Of The New Design Concept}

Fig.1 shows a "mountain-climbing chart" which was a method used for proposing the "new design concept" for the new scooter type. This mountain-climbing chart is roughly composed of two sections.

The first half consists of (1) an analysis of the scooter customers' sense of value, categorizing the scooter customers by different sets of values, (2) preparation of an image relation diagram that associates the customers' image of scooters, and (3) preparation of a positioning map that confirms the design's position in the scooter market.

From the results that were obtained, an issue was extracted that required more consideration and has to be overcome in the implementation stage. Namely, (1) the detailed categorization provided by the analysis of the customers' sense of value was not fully utilized in (2) the preparation of the image relation diagram, and moreover only generalized solutions were extracted.

For example, (2) in the stage of preparing an image relation diagram, objectivity can be maintained when the focused sections of the scooter and open questions from the customers are processed into data which is then grouped according to categorical principle component analysis. However, when it comes to preparing an image relation diagram by arranging the linguistic word groups based on the grouping results, the positioning of words or directions of vectors are not standardized and the preparation of such a relation diagram is largely dependent on the personal, subjective views of the one who prepares it. [11, 12]

Having said that, in the latter half of this study, the customers' tastes and product images were arranged according to their sense of value and grasped more objectively, so as to create the targeted "new design concept". In that process, a fresh sense of value can be created and then reflected in product planning. Last of all, the "Product Planning Business Approach Model - A-POST" will be proposed which encompasses these design business processes. 


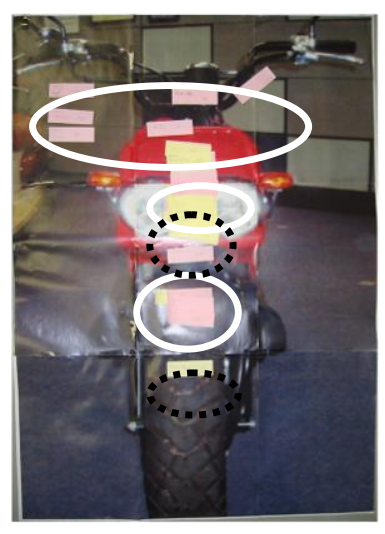

Front part

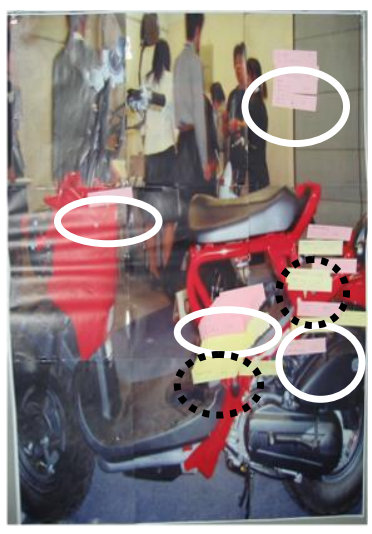

Side part

Fig.4: Example of visualization of the customers' preferences and tastes (Object Scooter 1)

\subsection{Analysis Of Customers' Sense Of Value}

In order to explore the sense of value of those who purchase a scooter, the authors conducted an awareness survey of scooter purchase behavior (4-step evaluation on a total of 21 survey items) on residents in the Tokyo Metropolitan area. (A total of 150 people between the ages of 16 and 28 were surveyed, of which 148 valid answers were obtained). Questions such as, "Would you like to buy a standard model?" were asked.

The data obtained from this survey were categorized through cluster analysis (Ward method and squared Euclidean distance) into differentiated groups which then were provided with meaning by means of principle component analysis (correlation matrix), for the purpose of exploring the customers' sense of value.

An example of the results from this principle component analysis is shown in Fig.2. The figure is plotted for 2 groups (Group A and Group B) to present the qualitative strata of the "customers' sense of value" separated by cluster analysis. As can be seen in the (a) dispersed chart of principle component points in the figure (on the left), Groups A and B are clearly separated, which can be explained in connection with Principle Component 1.

What gives meaning to Principle Component 1 is the (b) dispersed chart for the amount of factor load in the figure (on the right).

Extrapolating from this figure, Group A is associated with such keywords or phrases as will purchase after comparative consideration (Compare / Consider), will acquire as much information on the product as possible before purchasing (Product information), will find satisfactory functions and performance (Function / Performance) and so on, indicating that this group has an "interest or preference" in the scooter. On the other hand, Group B is grouped in association with such preferences as might compromise and purchase a low price product (Compromise / Low price), will purchase an inexpensive product in any case (Anyway inexpensive), will purchase a standard model (Standard), and will purchase after visiting only the nearby shops (Nearby). This suggests that this group has weak "interest or preference" toward the scooter.

Following a similar pattern, each of Groups A and B was further segmented into a total of 6 clusters, and each of them was characterized by means of principle component analysis.

As shown in Fig.3, the authors designated Group A as the "Very Interested Group" and Group B as the "Not Interested Group". Similarly, the 3 clusters under Group A were labeled as $\left(\mathrm{A}_{1}\right)$ selective purchasers, "Considerate", 
who give much consideration, $\left(\mathrm{A}_{2}\right)$ individualistic purchasers, "Individual", who are looking for something different from others, and $\left(\mathrm{A}_{3}\right)$ function and performance-oriented purchasers, "Functional", who place emphasis on functions and performance, respectively.

Furthermore, the 3 clusters under Group B are labeled as $\left(\mathrm{B}_{1}\right)$ trendy purchasers, "Fashionable", who are trend-savvy, $\left(\mathrm{B}_{2}\right)$ low price product purchasers, "Inexpensive", who are keen on finding low price goods, and $\left(\mathrm{B}_{3}\right)$ life commodity purchasers, "Necessity of life", who consider a scooter only as a means of transportation.

\subsection{Visualization Of Customers' Tastes}

In this section, the authors also conducted a survey of the same 150 respondents to the sense of value survey above regarding four scooter types popular among the young generation for the purpose of exploring their preferences for each type and tastes (likes and dislikes). In order to visualize the analysis results, Post-It notes were stuck to the targeted focus area that corresponded to the customers' tastes or preference and the reason for it was also written down.

Fig.4 shows an example of the customers' tastes being visualized. The area where pink-colored Post-It notes are stuck (the section circled with a solid line in Fig.4) indicate the areas which the customers like along with the reasons for their preference, while the areas with a yellow-colored Post-It note (the section circled with a dotted line in Fig.4) is and area the customers do not like.

By coloring the preferences in this way, clear visualization was realized. The visualized results of the survey of four different scooter types suggested that the customers pay more attention to the front part of a scooter than the rear part. Next, a more pointed focus was directed to the open questions given to two of the four types surveyed which gathered more pink-colored Post-It notes, indicating that more people liked them, and an analysis was conducted on the observations in Chapter 3.

\section{EXTRACTION OF A NEW DESIGN CONCEPT}

\subsection{Text Mining Studio (TMS)}

With a view to solving the issue raised in the first half of this study, an image relation diagram was prepared for each group's sense of value so that the subconscious feelings of the users could be grasped. In order to conduct an objective analysis, the authors employed a text mining method that is designed to analyze the customers' opinions as they exist linguistically. Specifically, the tool used was a text mining studio.

The text mining studio is a tool that is capable of indicating the intensity of association between words and between a word and its attribute and then analyzing the linguistic data as it exists. The intensity of association between words, as well as that between a word and its attribute can be obtained through calculation of the reliability that intensifies these associations. ${ }^{\mathrm{I}}[13-16]$

When the results of the reliability calculation show a value over 0.6 , then this data can be converted into a relation diagram. By employing this logic, more objective analysis is possible.

\subsection{Text Mining Analysis}

In the analysis of the customers' sense of value, based on their depth of interest (preference) in a scooter, the customers were roughly (1) divided into two groups which then were more specifically categorized (2) into six clusters (selective / consider, individual, functional, fashionable, inexpensive, and necessity of life).

In this section, the authors will call the (1) analysis of the open questions from these two roughly divided groups the "macro analysis", and the (2) detailed analysis of the open questions from the six clusters the "micro analysis". The authors will then carry out both a "macro" and "micro" analysis of the favorable opinions for the two 
preferred scooter types. The authors believe this will make it possible to grasp the customers' tastes more specifically.

The following section discusses the analysis results of the open questions obtained from these two types.

\subsection{Analysis Results}

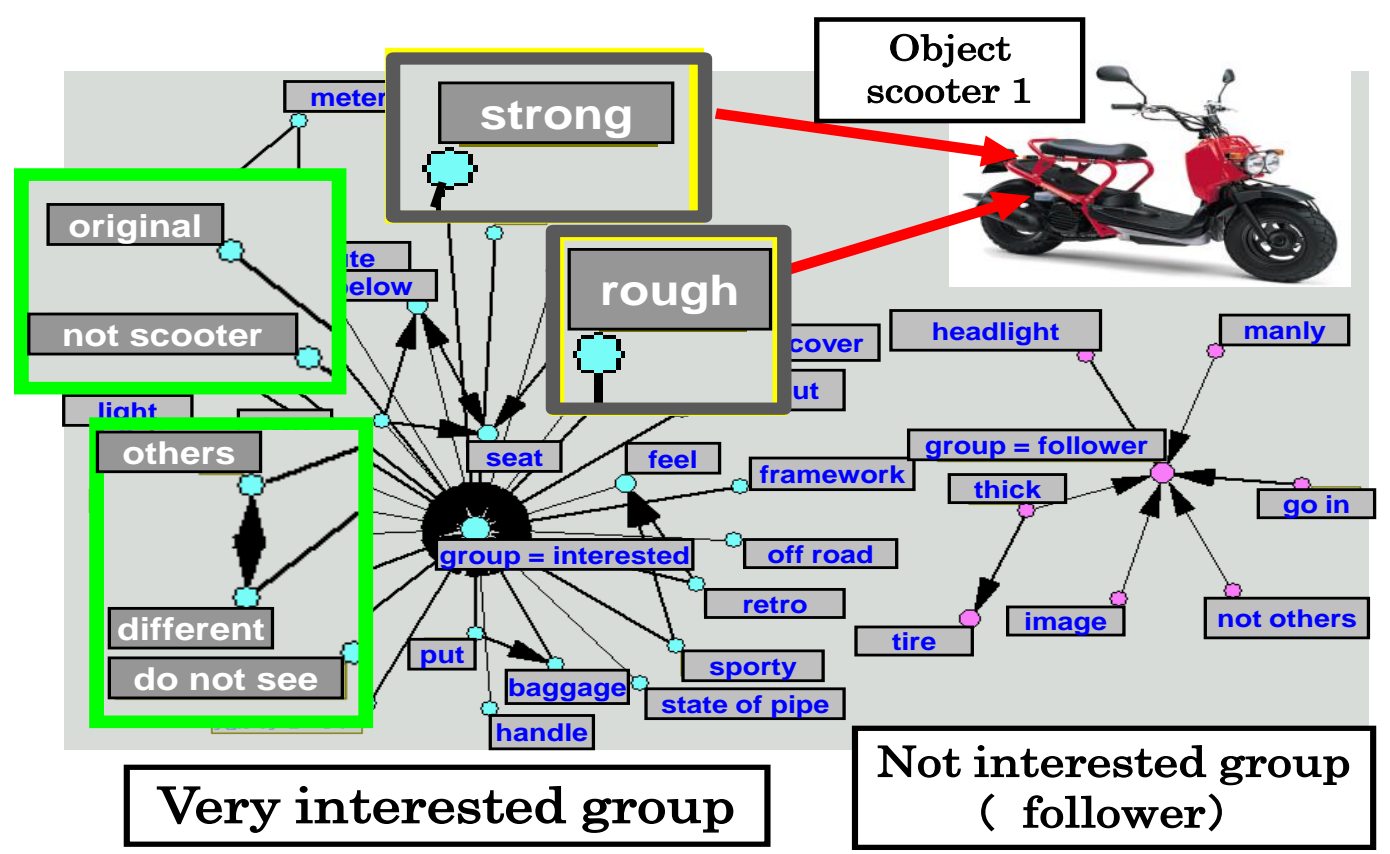

Fig.5: Result of the macro analysis of those who preferred object 1

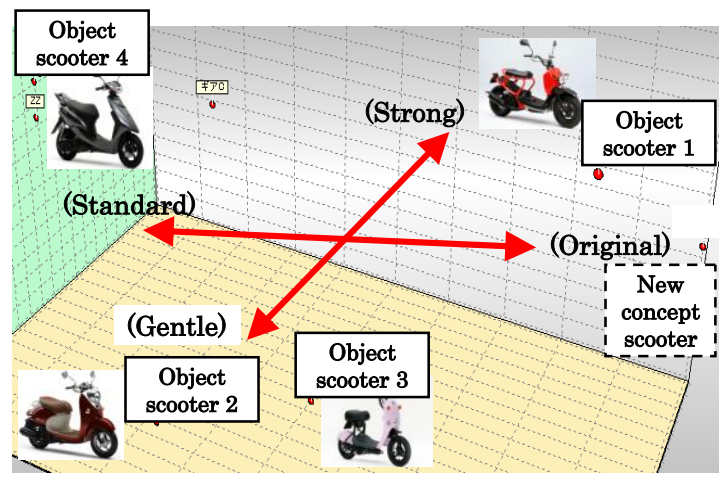

Fig. 6: Result of mapping based on the scooter form

Fig.5 shows an example of the analysis results obtained by text mining. The figure shows the macro analysis results from those who preferred Object 1 . The keyword network diagram on the left is for the "Very Interested Group" and the one on the right is for the "Not Interested Group (Follower)". On these diagrams, the intensity of association is not shown by the distance, but by the thickness of the connecting lines. 
In the network diagram for the "Very Interested Group", such expressions as "different from others", "do not see", "original", "not scooter", and so on can be found, suggesting that there is a part of the scooter which gives an impression to the customers that this type is different from other types. This particular part is located around the side frame underneath the seat and was found through the visualization of customers' tastes. This analysis result seems to indicate that this part of the scooter gives a strong impression unlike other types.

Other words that were associated with "different from others" were inferred to be "strong" and "rough".

Following the above pattern, a micro analysis of those who preferred Object 1, a macro analysis of those who preferred Object 2, and a micro analysis of those who preferred Object 2 were also conducted. The following is an outline of those analysis results. When it comes to the micro analysis results for those who prefer Object 1 , here again such words as "strong" and "rough" appear on the keyword network diagram, indicating that these words represent well the opinions of those who are looking for a distinct type that stands out from other types.

Also, it was inferred that the selective / consider purchasers (those who collect product information in advance and make careful consideration) prefer this type because of the space for luggage. Overall, it was revealed that Object 1 gives a fresh impression unlike the preceding types, and this is reflected in image relation words such as "strong" and "rough".

Next, the authors will consider the results of the macro analysis of those who preferred Object 2. The survey results indicate that the majority like this model because the design is "round-shaped and cute". Here, on the keyword network diagram for the "Not Interested Group (Follower)" such words as "round" and "cute" are found, but these words are not found on the keyword network diagram for the "Very Interested Group". On the other hand, the words that do appear in the keyword network diagram for both the "Very Interested Group" and the "Not Interested Group (Follower)", while at the same time are used only in regard to Object 2 are "gentle" and "moderate".

Last of all are the results of the micro analysis of those who preferred Object 2. In this analysis also, the expressions "gentle" and "moderate" have been extracted from a number of clusters. These words appear in the opinions from the selective / consider purchasers and the fashionable purchasers (those who focus on recent trends).

Based on the above results of the macro and micro analyses of those who prefer Object 2, the reason why the majority of customers like Object 2 is inferred to be associated with words such as "gentle" and "moderate".

\subsection{The Creation Of A New Concept}

The authors next set out to create a design concept for a new scooter type that incorporated the results of the text mining analyses cited above.

The target customers for this new product development project are the young generation, and therefore it is important to create a concept based on the keywords used by young customers.

Therefore, the authors focused on the word "strong", the impressive image obtained from the text mining analysis for Object 1, as well as the word "gentle", the image obtained from a number of customers clarified through the text mining analysis for Object 2. The authors then combined these words and created a concept of "strong gentleness".

This new design concept was approved by the product planning / designing department of our consigned motorcycle manufacturer, and the type was launched as a newly designed scooter.

\subsection{Verification Via A Positioning Map}

In order to confirm that the design concept created above for developing a new scooter is truly a new 
concept, the authors compared it to the vehicle forms of existing types (adding another 8 types to the 4 types surveyed, for a total of 12 types) and verified the results using a positioning map.

The areas of the scooter design used for comparison were determined by considering the focus areas from the visualization of customers' tastes. In the compared areas, a corresponding location was given 1 point, which then was converted to $0-1$ data.

The data were then analyzed by quantification theory type III and subjected to mapping. Consequently, the authors confirmed that we were able to create a new design that is "original" and "strong gentleness". Fig. 6 shows the results of mapping based on the scooter body form.

\section{PROPOSAL OF THE PRODUCT PLANNING BUSINESS MODEL, “A-POST”}

The authors hereby propose the product planning business model using text mining as discussed above as “A-POST" (Amalab's Product Development Model of Scooter by the Text Mining Method).

Along with the outline of "A-POST" shown in Fig. 7, below is an explanation of "A-POST".

\subsection{Research}

First, a survey of the customers' sense of value and a design styling survey are conducted for the purpose of grasping the customers' purchasing behavior and the points of product that they focus on, as well as the reasons that they focus on these areas.

The analysis of the customers' sense of value is to find out the consciousness and sense of value the customers have when making a purchase. The design styling survey is for finding the areas of the product that the customers pay attention to and the reasons why they pay attention to them on an open question basis.

\subsection{Step1: Classification Of Customers' Sense Of Value}

By analyzing the results of the customers' sense of value survey through statistical methods, the customers are categorized by their sense of value. In the study case here, after stratifying the customers via cluster analysis, each group and each cluster was given meaning by means of principle component analysis, so that the customers could be categorized by their sense of value.

\subsection{Step2: Visualization Of Customers' Tastes And Text Mining Analysis}

Through visualization of the areas of the product that customers focused on and by applying the text mining method to the open questions drawn from the customers, key characterizing words are extracted. By employing the text mining method, an analysis of open questions, which tends to be influenced by the subjective views of the analyst, can now be conducted objectively. 


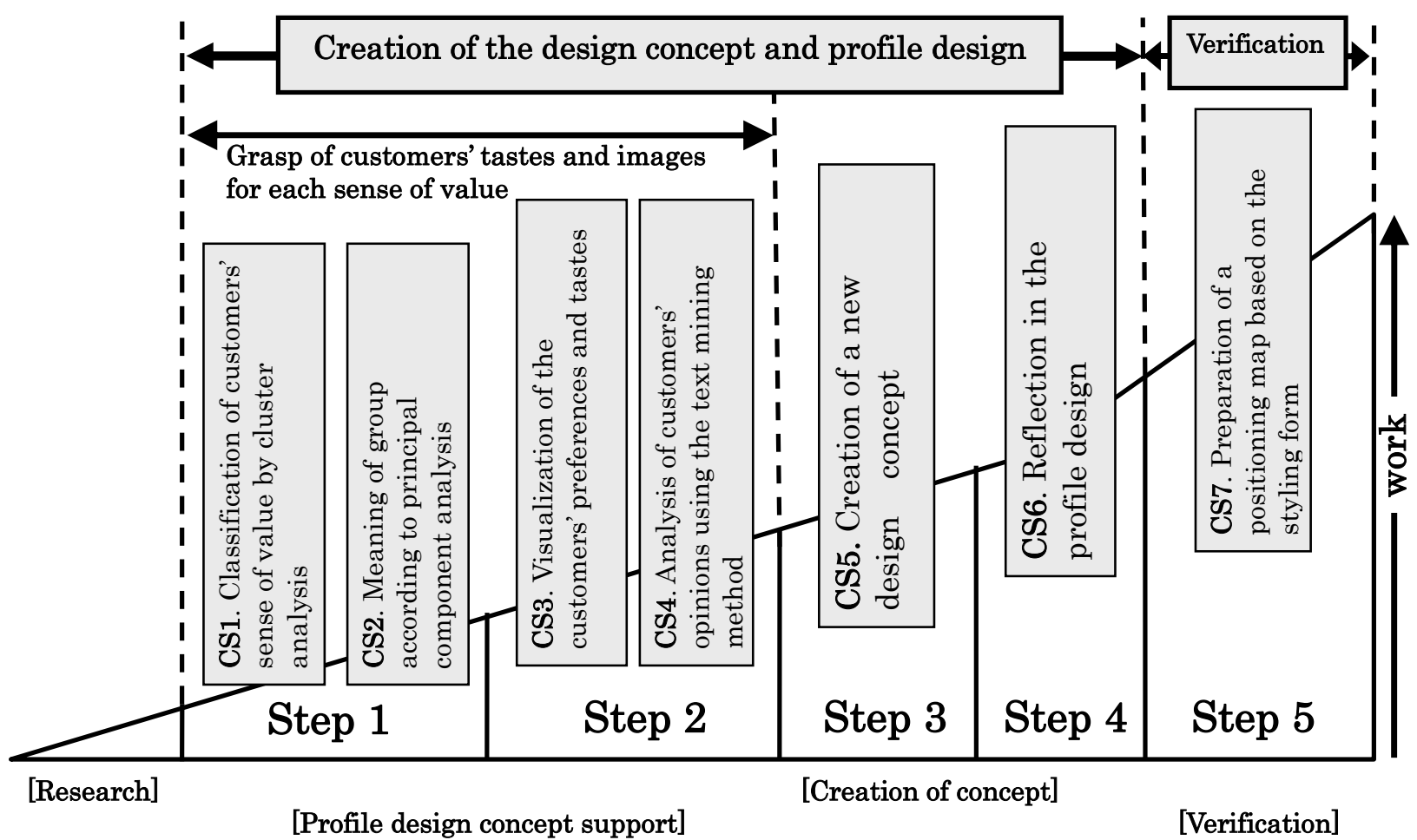

Fig.7: The product planning business model "A-POST"

The process of Step 1 and Step 2 above is for grasping the customers' tastes and images based on their sense of value.

\subsection{Step3: Creation Of A New Concept}

Using the characterization words extracted in Step 2, a new design concept is created. It is important for a new design concept to be expressed by image carrying words used by the target customers during the product development.

\subsection{Step4: Reflection In The Profile Design}

The new design concept created in Step 3 is reflected in the profile design of the product. The visualization of the areas of the product the customers focus on and open questions analysis conducted in Step 2 enables the design team to grasp which areas of the product give the impressions expressed with which image carrying words, and thereby objectively support the profile design process.

The process above consisting of Step 1 to Step 4 is for the creation of the design concept and the profile design.

\subsection{Step5: Preparation Of A Positioning Map}

Last of all, verification is carried out to check if the product that has been developed through the above steps is within the estimated design range by means of a positioning map. In this case, a positioning map was prepared based on the scooter styling forms, and the created design concept was confirmed to be reflected in the profile design. 
The flow of the business process, starting from a series of surveys to the verification of the design concept, has been proposed as "A-POST".

\section{CONCLUSION}

In this study, the authors have proposed the product planning business model, "A-POST" which incorporates the text mining method to analyze customers' opinions as they exist linguistically in order to enable the creation of a design concept and profile design for a new scooter type.

Based on the study results above, product development was carried out at Manufacturer A, and the new type scooter was launched in the market. The type has been favorably received due to its design, storage space, and functionality.

\section{ACKNOWLEDGEMENTS}

This is to acknowledge the cooperation rendered from Naoya Ushikoshi, Takuya Ishizuka, and Keita Kato of Aoyama Gakuin University College of Science and Engineering.

\section{APPENDIX}

I) Equation for the reliability calculation:

$$
\begin{aligned}
& \text { Extraction of association between words } \\
& \qquad P_{i j}=\frac{n\left(W_{i}, W_{j}\right)^{a)}}{n\left(w_{i}\right)^{b)}} \\
& \text { a) } \mathrm{n}(\mathrm{Wi}, \mathrm{Wj}) \text { : number of lines, n, where Word Wi } \\
& \text { and Word Wj appear concurrently } \\
& \text { b) } \mathrm{n}(\mathrm{Wi}): \text { number of lines, n, where Word Wi }
\end{aligned}
$$
Extraction of association between a word and

its attribute

$$
P_{i j}=\frac{n\left(r_{i}, W_{j}\right)^{c)}}{n\left(W_{i}\right)^{d)}}
$$

c) $\mathrm{n}(\mathrm{r}, \mathrm{Wj})$ : number of lines, $\mathrm{n}$, where Word $\mathrm{Wj}$ appears in Attribute ri

d) $\mathrm{n}(\mathrm{Wi})$ : number of lines, $\mathrm{n}$, where Word Wi

$\mathrm{P}:$ reliability, r: attribute, w: word, appears $\mathrm{n}$ : number of lines

\section{AUTHOR INFORMATION}

Mari Nakamura is a graduate student of the School of Science and Engineering at Aoyama Gakuin University.

Masato Kuniyoshi received his Master of Engineering degree from the School of Science and Engineering at Aoyama Gakuin University.

Manabu Yamaji is a research associate in the School of Science and Engineering at Aoyama Gakuin University, Japan. He received his Master of Engineering degree in Graduate School of Information Systems at University of 
Electro-Communications in 1999. His current research and teaching interests are in the general area of production engineering. In particular, he is interested in Total Quality Management, Computer Aided Engineering.

Kakuro Amasaka is a Professor in the School of Science and Engineering at Aoyama Gakuin University, Japan. He received his Ph.D. degree in Precision Mechanical and System Engineering, Statistics and Quality Control at Hiroshima University in 1997. His current research and teaching interests are in the general area of production engineering. In particular, he is interested in New JIT. He is a member of POMS and EurOMA.

\section{REFERENCES}

1. Amasaka, K., Constructing a Customer Science Application System 'CS-CIANS'- Development of a Global Strategic Vehicle 'Lexus' Utilizing New JIT -, WSEAS Transactions on Business and Economics, Issue3, Vol. 2, pp.135-142, 2005.

2. $\quad$ Amasaka, K., Science SQC, New Quality Control Principle, Springer.

3. Amasaka, K., Study Method of Customers' Sense of Value 'Customer Science', Concept Support Method of Strategic Product Development 'Design Technical Method', The Behaviormetric Society of Japan, The 32nd Annual Technical Conference, pp.241-244, 2004. (in Japanese)

4. Amasaka, K and Osaki, S., The Promotion of New Statistical Quality Control Internal Education in Toyota Motor -A Proposal of 'Science SQC' for Improving the Principle of TQM, European Journal of Engineering Education, Research an Education in Reliability, Maintenance, Quality Control, Risk and Safety, Vol. 24 No.3 , pp.259-276, 1999.

5. Amasaka, K., The Validity of Advanced TMS, A Strategic Development Marketing System Utilizing New JIT, The International Business \& Economics Research Journal, Vol.6, No.8, pp.35-42, 2007.

6. Okabe, Y., Yamaji, M. and Amasaka, K., Research on the Automobile Package Design Concept Support Methods 'CS-APDM', Proc. of the 11th Annual International Engineering Theory, Applications \& Practice, Nagoya, pp.268-273, 2006.

7. Amasaka, K., The Validity of TDS-DTM: A Strategic Methodology of Merchandise Development of New JIT -Key to the Excellent Design 'LEXUS', The International Business \& Economics Research Journal, Vol.6, No.11, pp.105-115, 2007.

8. Amasaka, K., Study Group of Quality Management in the Manufacturing Industry, New Japan Model, Science TQM, Theory and Practice of Strategic Quality Management, pp.207-224, Maruzen, 2007. (in Japanese)

9. Frishammar, J., Managing Information in New Product Development: A Literature Review, International Journal of Innovation and Technology Management, Vol. 2, No.3, pp.259 - 275, 2005.

10. Fleisher, C., Wright, S., and Allard, H., The Role of Insight Teams in Integrating Diverse Marketing Information Management Techniques, European Journal of Marketing, Vol.42, No.6/7, pp.836-851, 2008

11. Chikamori, Y., Ushikoshi, N., Kuniyoshi, M., Ishizuka, T., Kato, K. and Amasaka, K., A Study on Customer Orientation for Strategic Product Planning, The Japan Society for Production Management, the 21st Annual Technical Conference, pp.241-244, 2005. (in Japanese)

12. Nakamura, M., Kuniyoshi, M., Yamaji, M. and Amasaka, K., Proposal and Validity of the Merchandise Planning Business Model 'A-POST', International Symposium on Management Engineering, pp.232-239, 2008.

13. Mathematical Systems Inc., Technical Information of Text Mining Studio, pp.19-21, 2005. (in Japanese)

14. Agrawal, R., Imielinski, T., Swami, A., Mining Association Rules between Sets of Items in Large Databases, Proc. of the ACM SIGMOD Conference on Management of Data, Washington D.C., pp.207-216, 1993.

15. Rickman, T. and Cosenza, R., The Changing Digital Dynamics of Multichannel Marketing: The Feasibility of the Weblog: Text Mining Approach for Fast Fashion Trending, Journal of Fashion Marketing and Management, Vol.11, No.4, pp.604-621, 2007.

16. Bose, R., Competitive Intelligence Process and Tools for Intelligence Analysis, Industrial Management \& Data Systems, Vol.108, No.4, pp.510-528, 2008. 
NOTES 